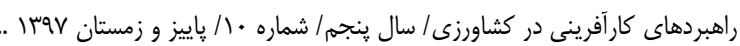

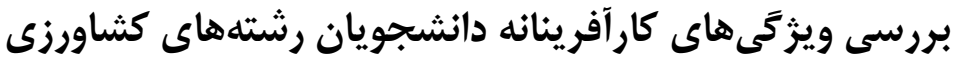

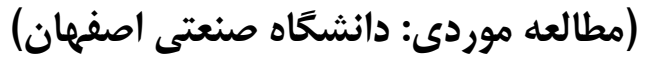

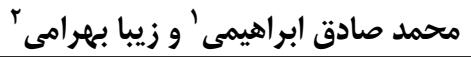

ا - استاديار دانشگاه صنعتى اصفهان، گروه توسعه روستايى، دانشكده كشاورزى، دانشگاه صنعتى اصفهان، (نويسنده مسوول: ebrahimi_ms@cc.iut.ac.ir)

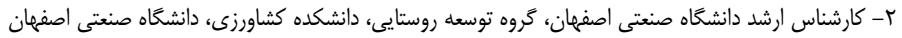

تاريخ دريافت:

صفحه: •1 تا 19 19

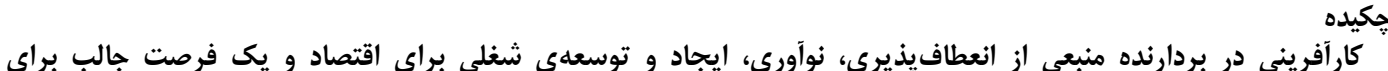

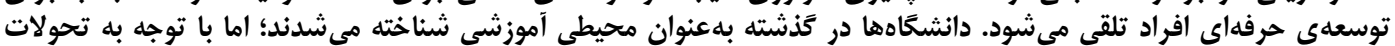

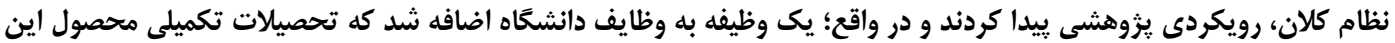

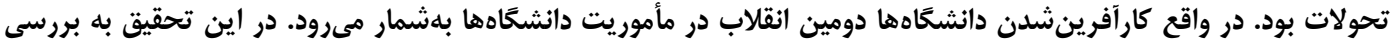

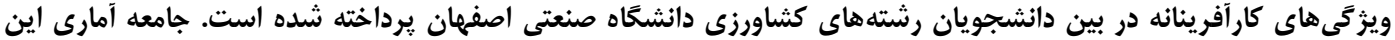

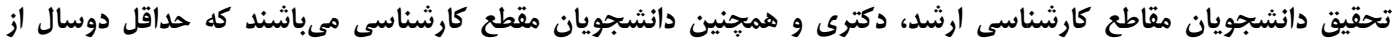

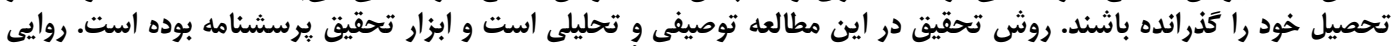

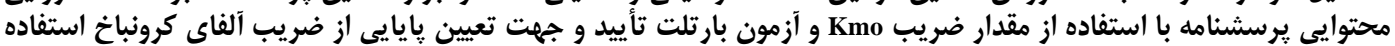

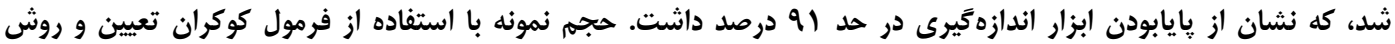

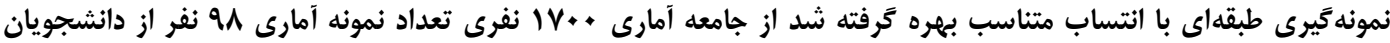

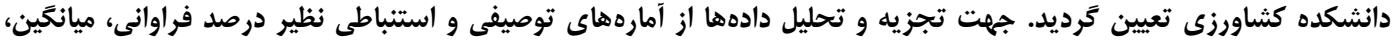

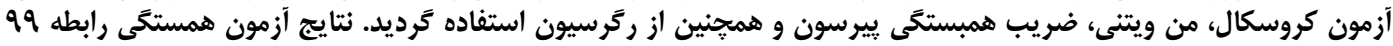

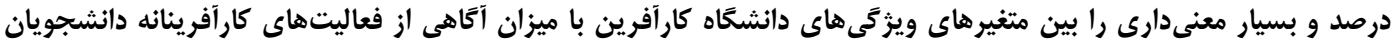

نشان داد.

وازههاى كليدى: نظام آموزشى، كار آفرينى، نوآورى، فرصت

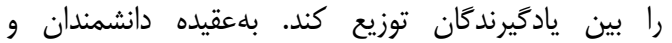

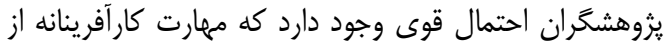

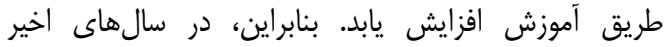

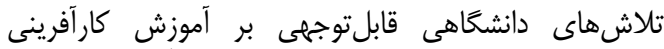

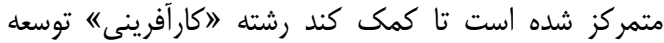

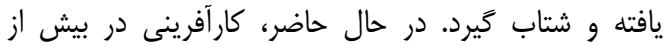
10...

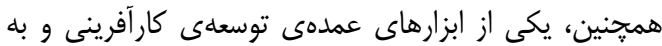

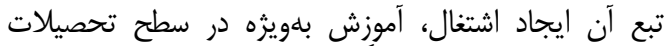

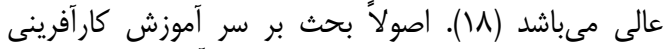

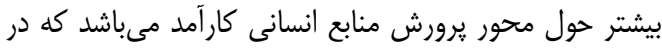

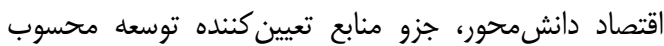

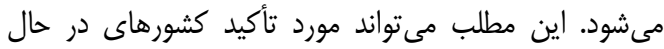

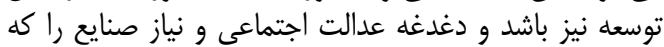

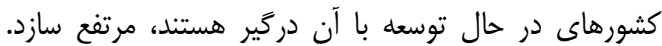

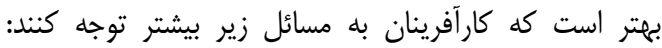

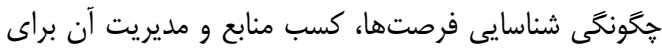

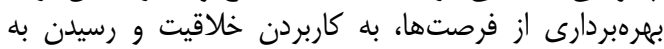

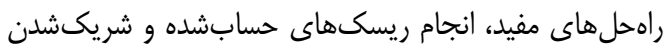

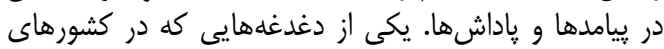

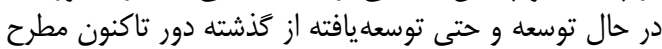

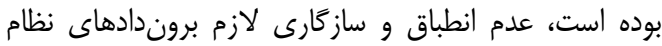

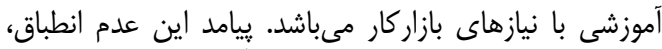

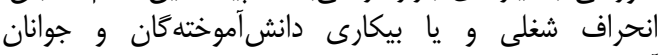
آموزشديده است كه باعث مى
مقدمه

در عصركنونى، مديريت بر سازمانها به شرايط محيط

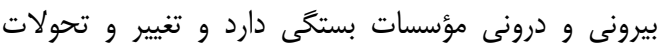

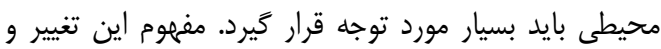

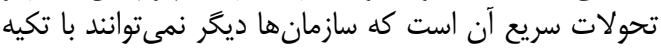

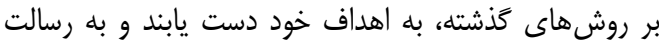

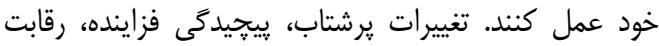

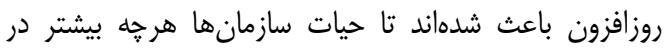

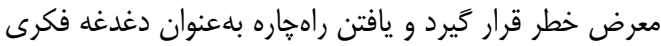

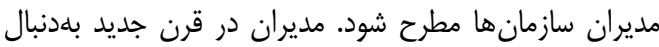

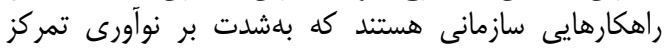

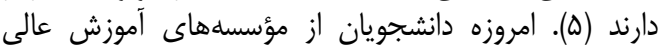

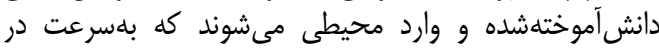

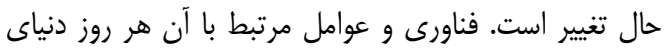

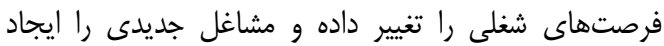

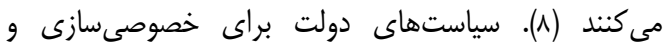

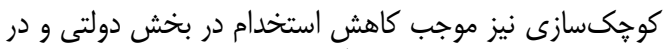

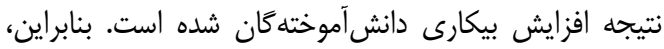

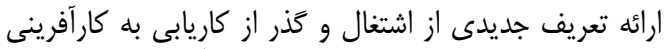
يكى از راهحلهاى معضل بيكارى دانش آموخته

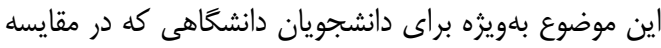

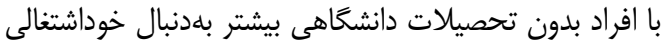

هستند بسيار اهميت دارد (عبا).

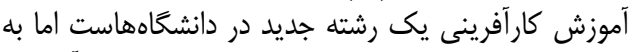
سرعت در حال بازشناسى است؛ و مى ارتواند فرهنى كار آفرينانه 
دانشآموخته كان كشاورزى خود را براى استخدام در مؤسسات

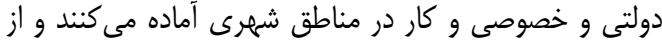

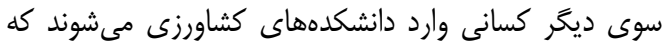

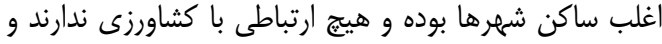

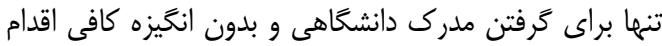

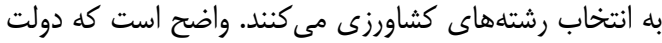

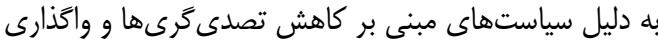

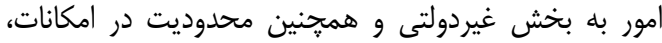

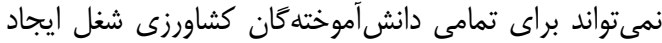

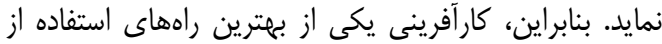

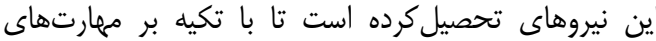

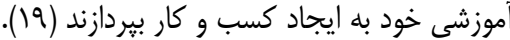

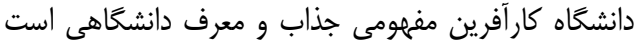

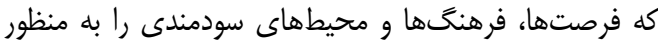

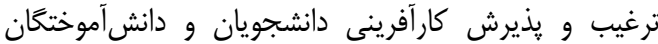

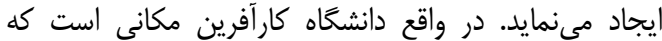

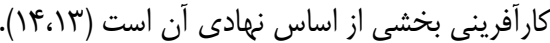

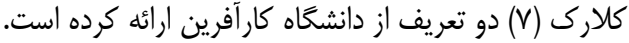

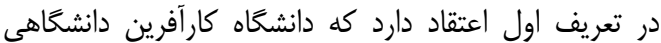

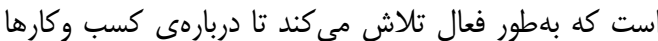

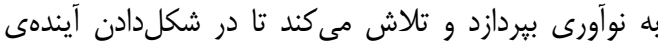

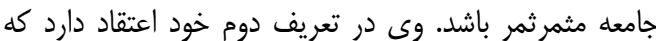

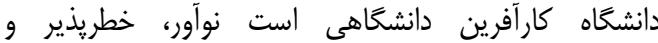
يرورشدهندهى رفتارهاى كار آفرينانه.

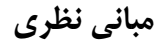

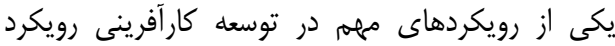

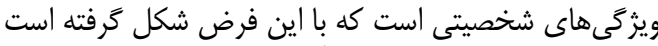

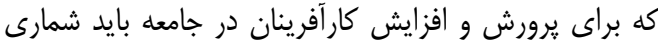

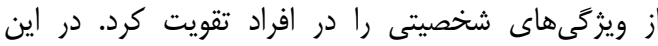

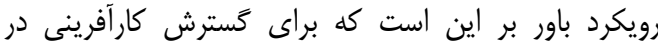

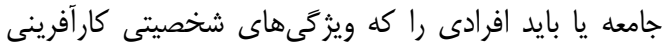

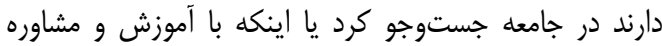

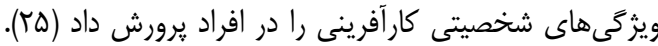

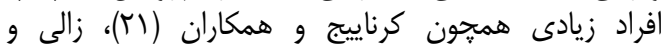

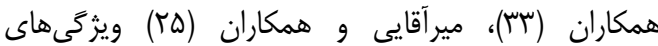

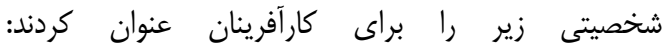

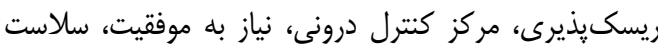

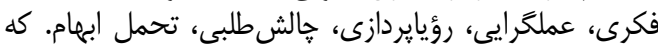

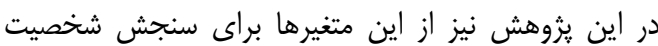
افراد مخاطب استفاده شد.
نظام آموزشى مورد ترديد قرار گرفته و زير سئوال برود (اس).

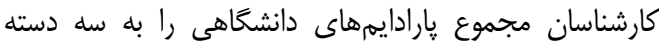
تقسيم مى كنند:

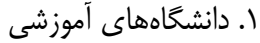

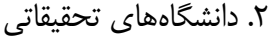

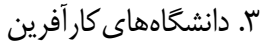

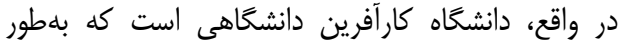

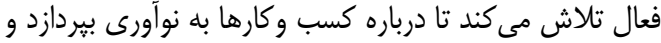

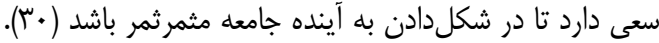

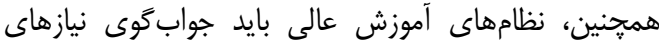

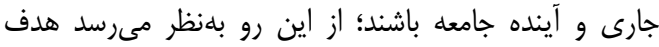

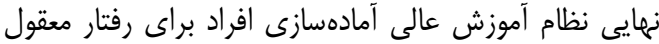

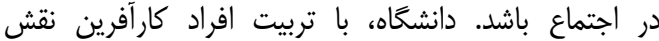

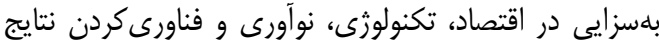

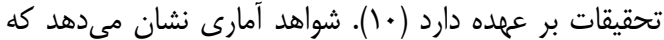

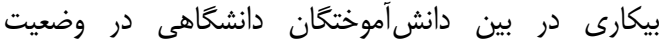

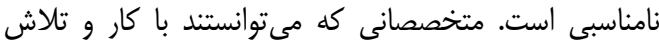

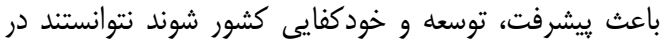

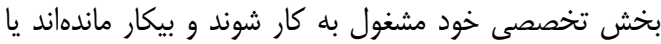

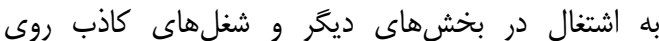
آوردهاند. ورود به دنياى بازار كار براى آن دآ دسته از دانش دانشجويانى

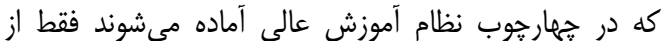

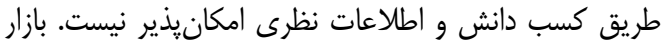

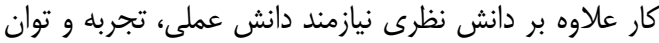

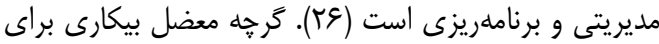

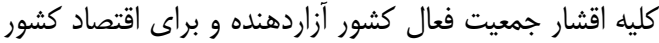

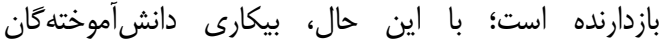

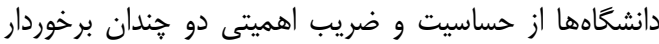

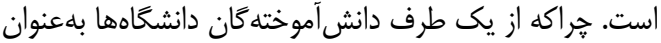

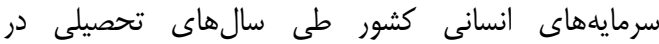

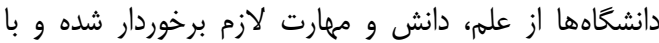

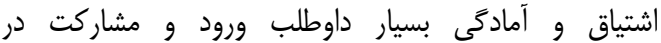

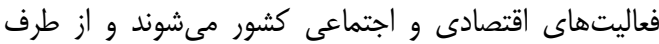

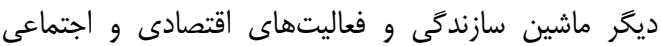

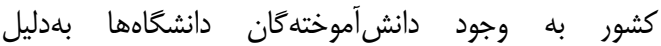

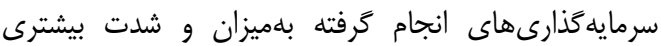

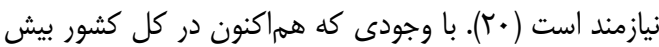

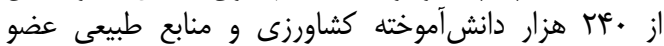

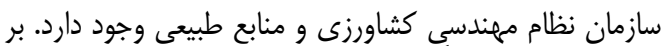

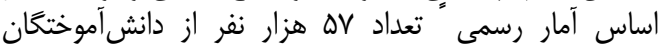

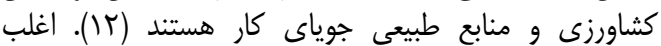




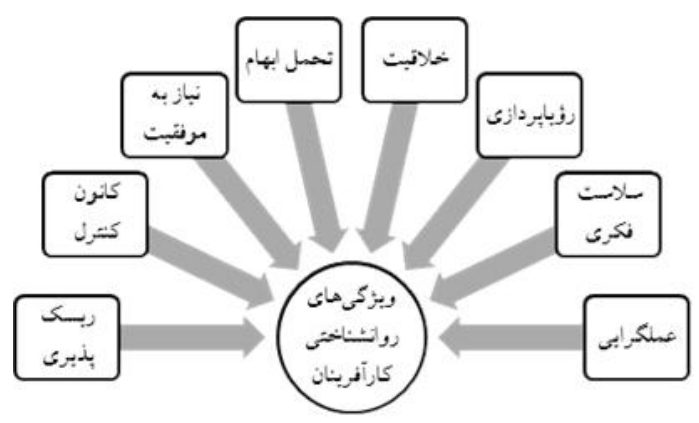

شكل 1- مدل مفهومى ويزگ هاى روانشناختى كار آفرينان

Figure 1. Conceptual Model of the Psychological Characteristics of Entrepreneurs

هـ عملَكرايي

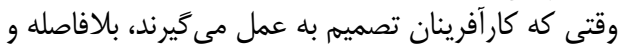

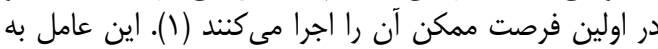

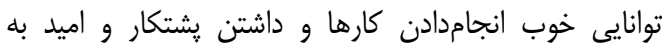

موفقيت در امور محوله به فرد اشاره داردا كارد (سب).

7- تحمل ابهام

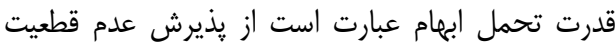

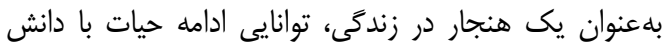

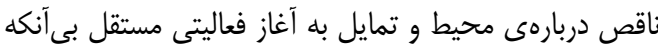

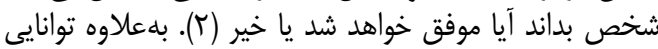

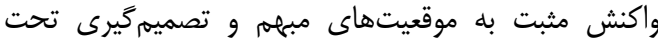

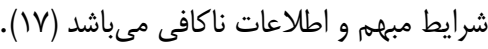

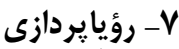

كارآفرينان از صرف وقى وقت خود بر روى إيده إيداى جديد

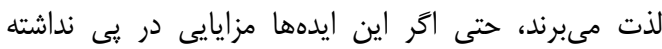

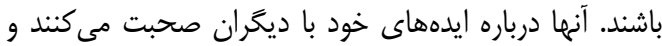

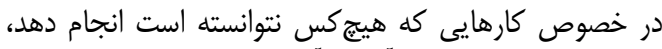

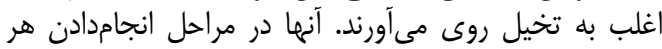

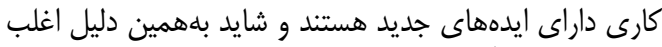

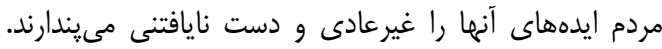

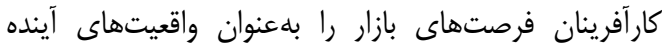

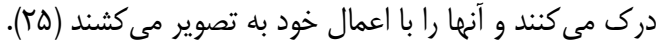

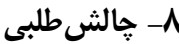

קالشطلبى درجهاى كه افراد در عمليات روزانه درگير

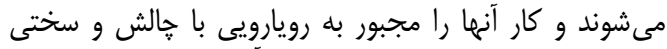

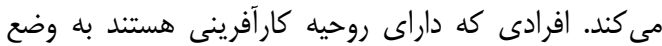

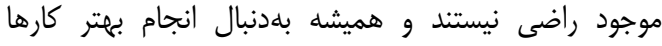

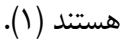

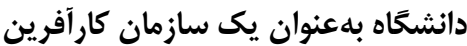

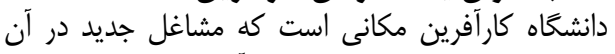

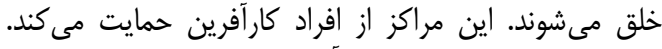

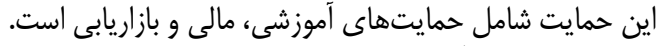

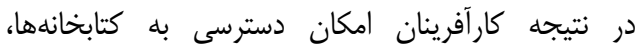

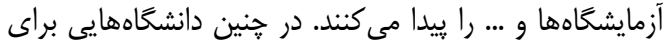

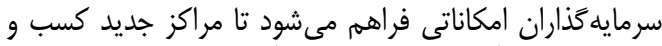

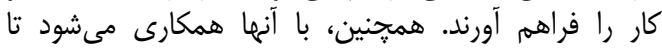

تعريف نظرى سازههاى مدل

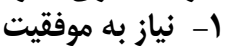

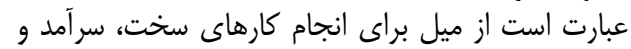

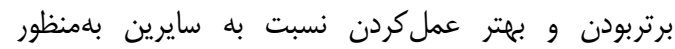

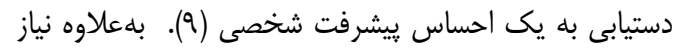

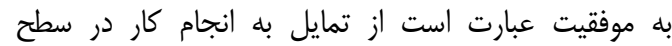
استانداردهاى عالى به قصد موفقيت در موقعيتهار است رقايت رقابتى.

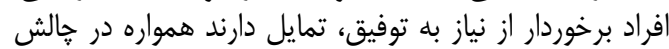

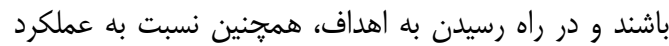

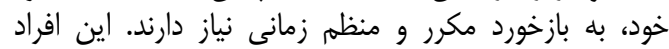

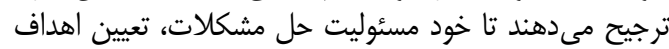

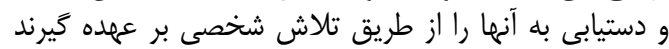

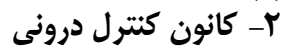

افراد با مركز كنترل درونى درونى معتقدند كه وقايع خارجى

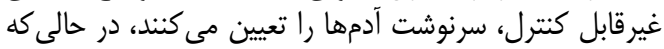

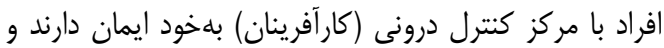

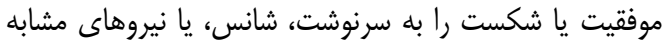

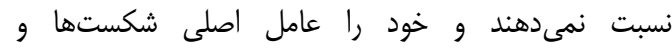
ييشرفتهاى خود مي دانند (10).

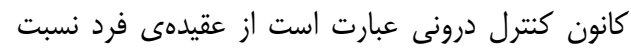

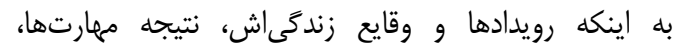

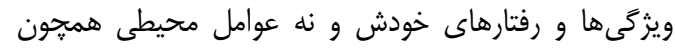

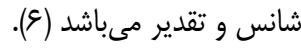

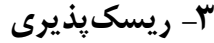

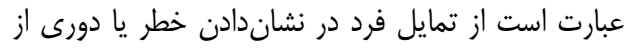

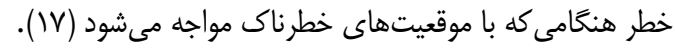

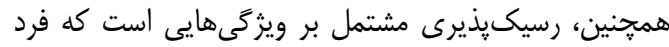

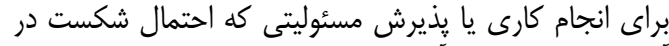

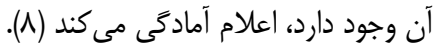

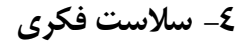

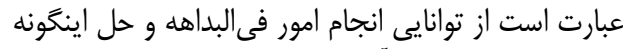

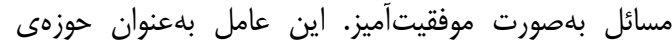

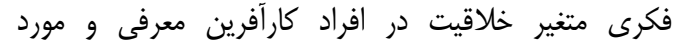
شناسايى قرار گرفته مىشود (سب). 


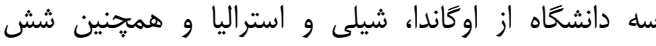

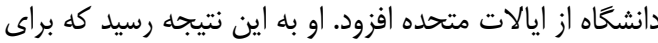

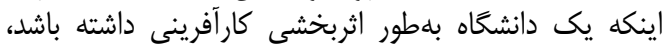

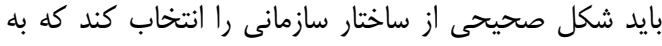

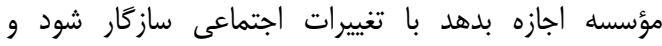

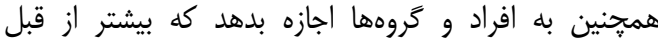

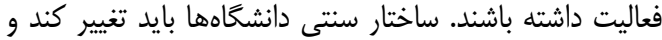

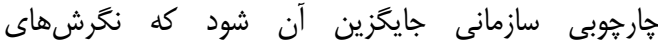

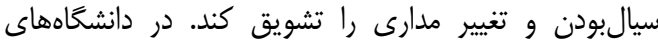

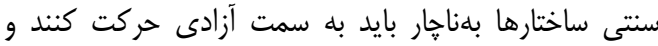

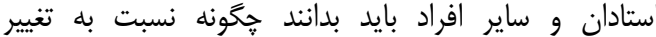
هوشمندانه رفتار نمايند (V)

مدل دانشعاه كارآفرين اتزكويتز (V) (II)

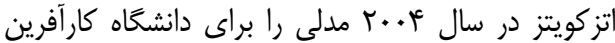

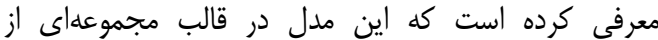

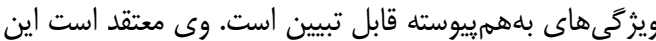

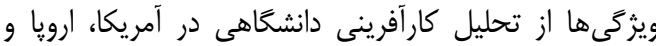

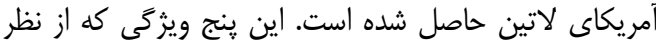

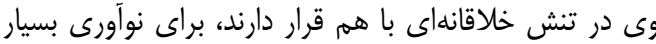

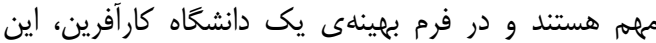

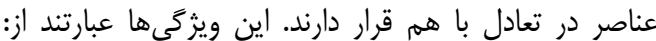

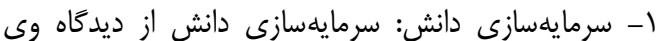

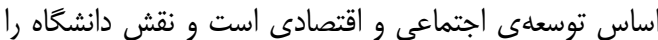

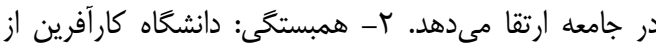

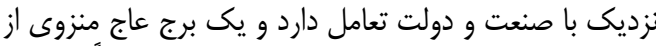

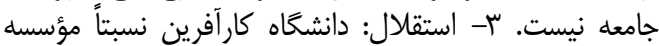

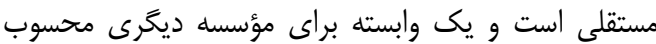

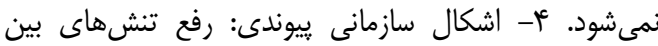

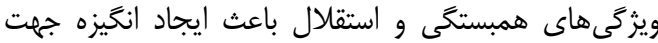

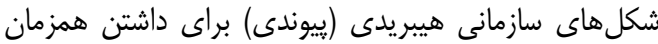

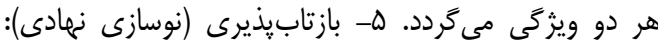

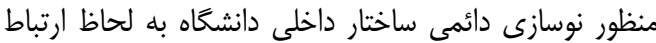

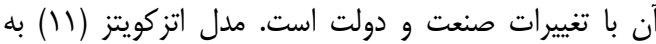

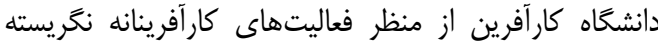

مدل دانشكاه كارآفرين روترمل و همكاران (Y^)

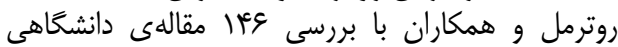

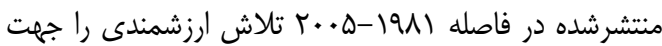

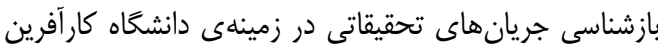

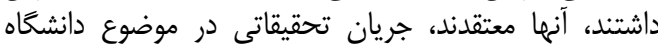

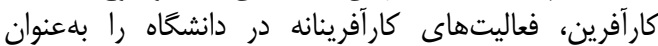

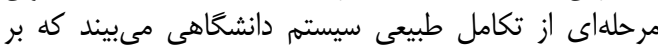

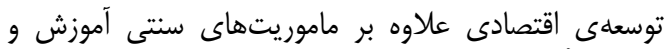

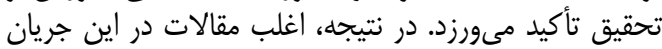

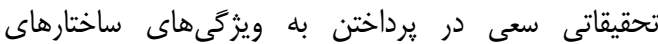

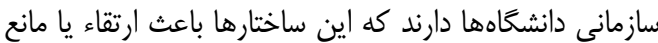

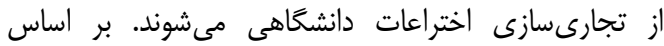

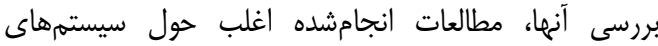

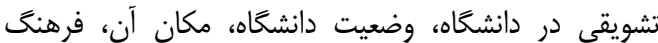

مشكلات آنها را ييشبينى كرده و از فرصتهاى بلدمست آمده

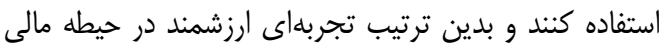

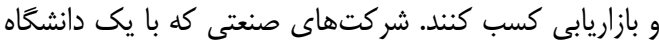

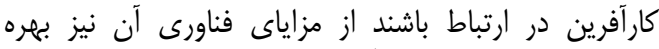

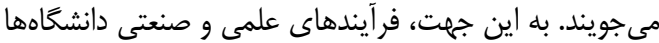

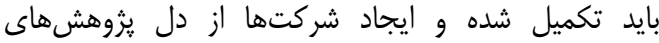

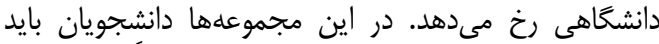

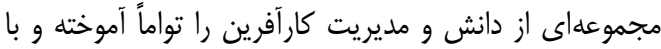

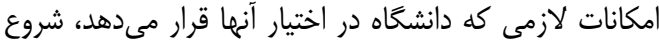

به فعاليت در عرصه صنعت نمايند (ج) (r).

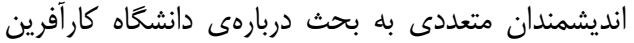

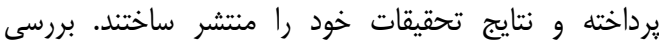

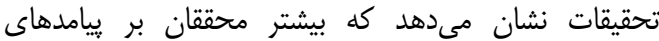

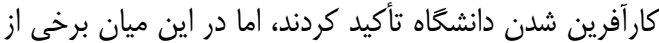

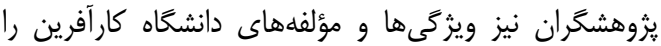

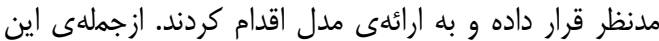

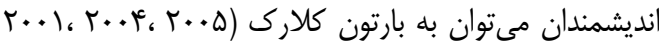

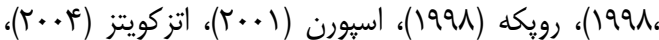

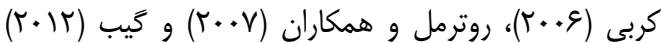

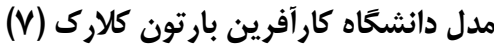

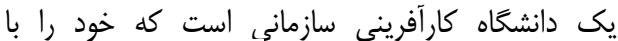

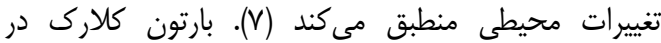

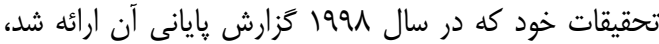

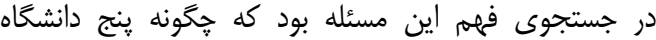

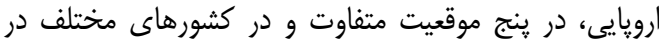

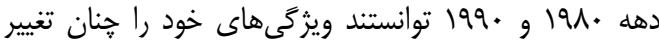

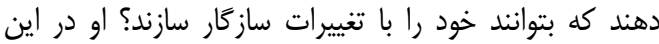

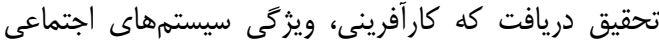

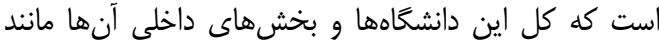

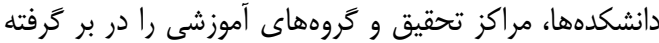

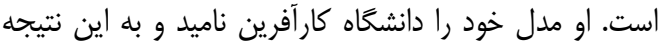

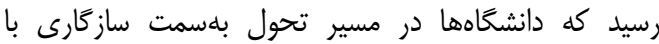

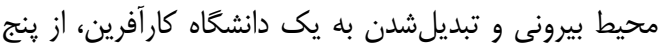

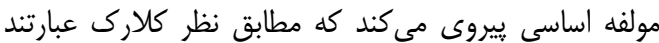

ا إيجاد هستهى رهبرى قوى: دانشعاه كارآفرين داراى

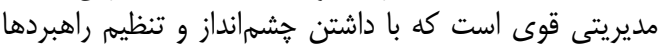

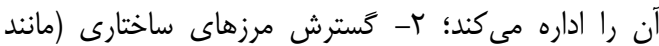

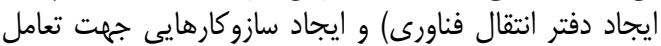

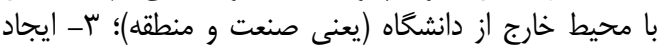

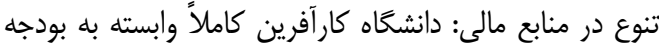

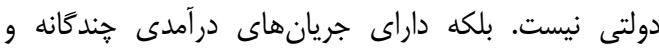

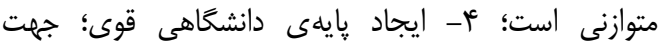

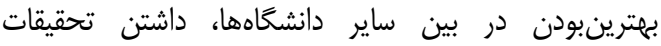

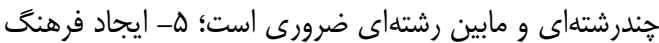

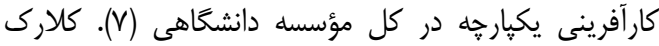

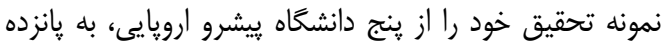

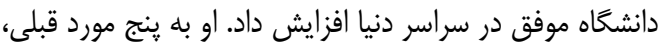




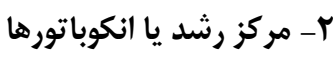

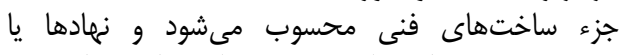

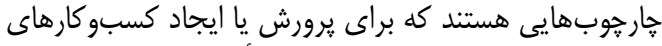

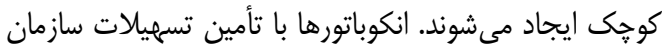

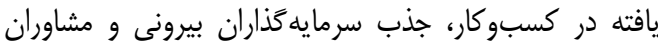

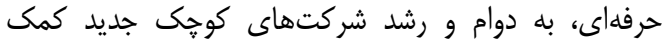

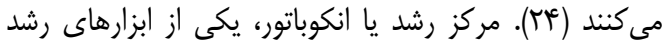

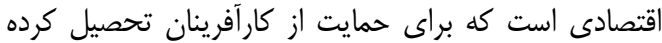

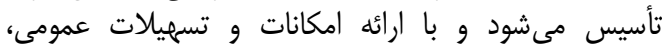

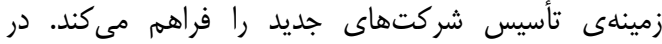

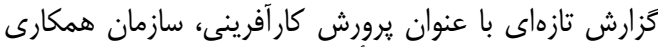

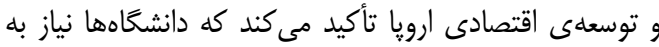

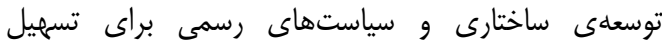

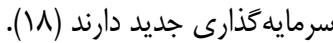

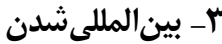
بينالمللىشدن اشاره به روابط ميان دولت- ملتهان الما دارد،

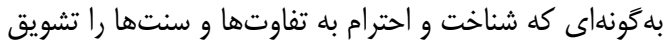

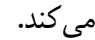

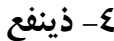

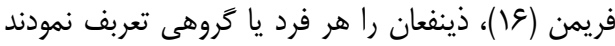

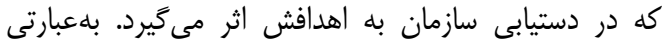
ديكر، ذينفعان را كروههايى مى دانداند كه براى برائ بقاء و موفقيت

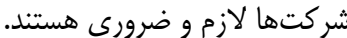

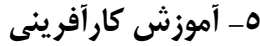

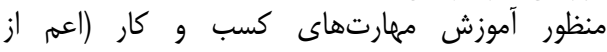
آموزشهاى تخصصى و عمومى) مى إشد كها كه براى سطوح

7ختلف جامعه ارائه مىشود (أ).

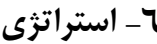

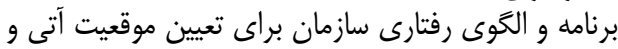

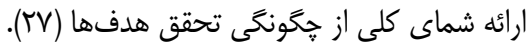

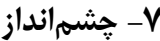

نقطه آغازين تعيين هدف در سازمانها ترسيه جشهمانداز

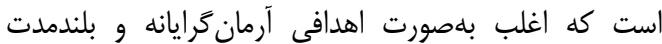

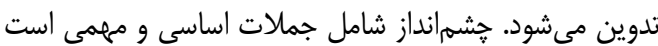

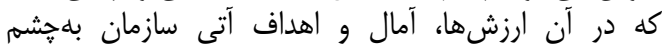

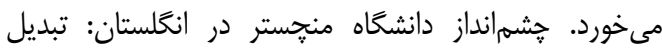

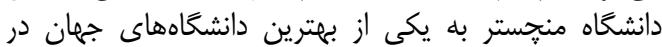

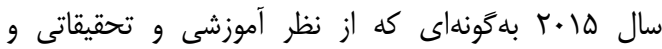

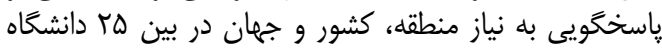
برتر جهان قرار داشته باشد (TV).

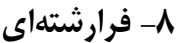

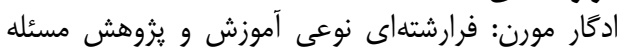

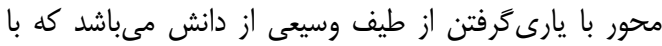

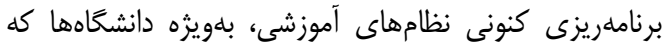

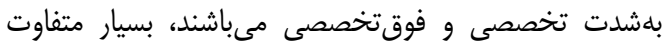

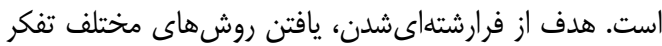

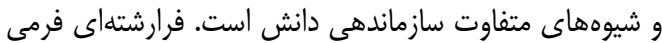

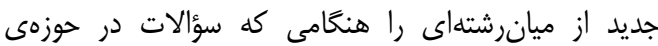
بينرشتهها مطرح هستند، ارائه مى دهد (T) (T).
حاكم بر دانشخاه، كارگزاران واسط در دانشخاه، تجربهى

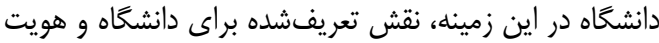

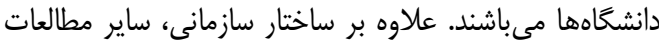

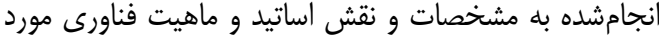

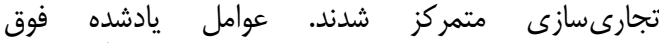

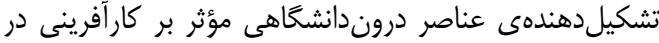

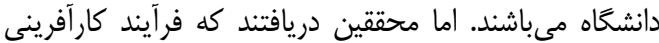

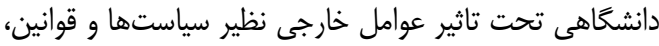

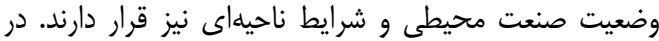

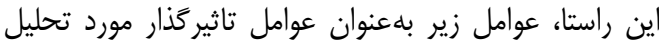

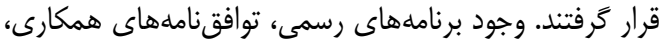

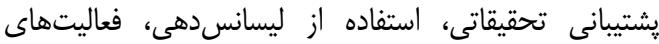

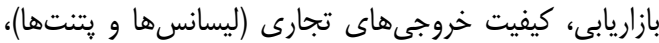

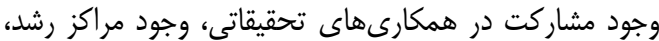

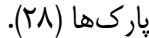

مدل دانشَاه كار آفرين آلان كيب (10) (1)

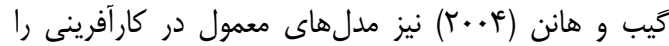

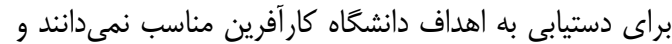

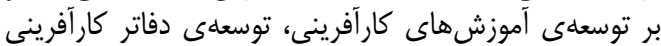

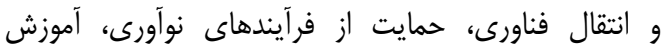

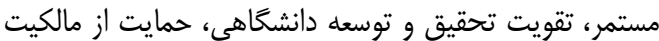

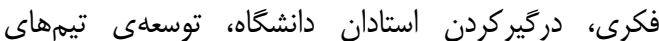

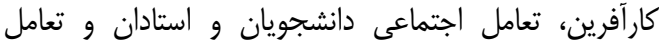

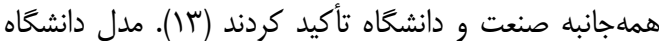

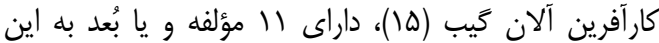

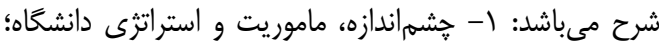

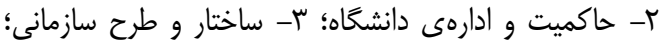

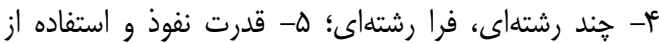

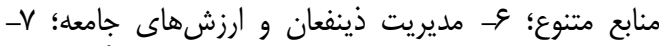

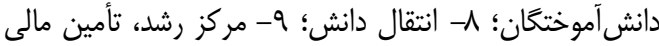

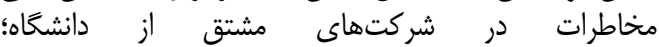

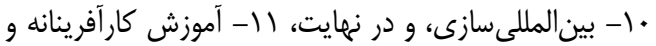

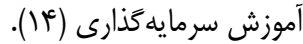

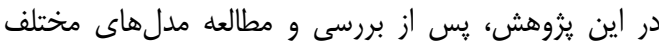

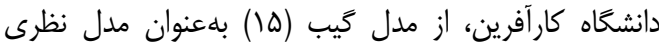

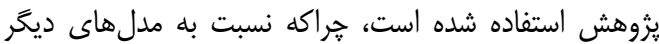

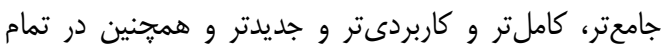
سطوح سازمانى قابل استفاده است.

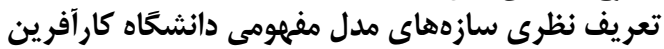
آلن تيب (10) با توجه به شرايط دانشكاه كارآفرين م مؤلفه از إز لا مؤلفه به شرح زير مورد بررسى قرار مى كيردان

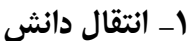

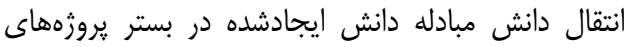

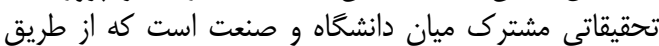

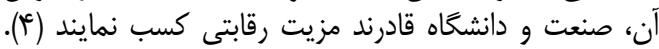

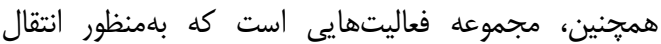
دانش سازمان ميان اعضا صورت مى گيرد (ए). 
بود كه با استفاده از فرمول كوكران با دقت احتمالى •9 درصد

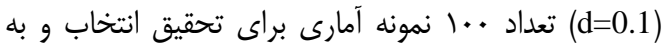

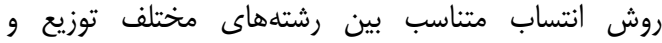

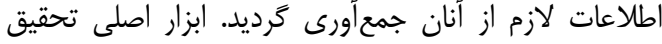

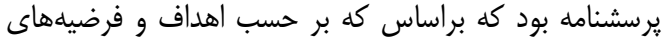

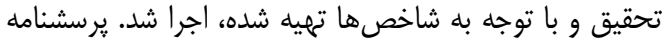

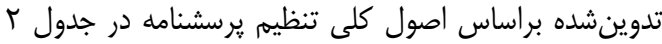

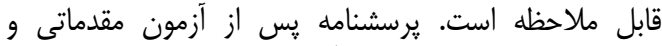

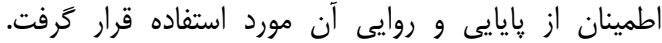

Table 1. Questions in the questionnaire

\section{مواد و روشها}

دانشگاه صنعتى اصفهان يكى از دو دانى دانشگاه بزرى استان

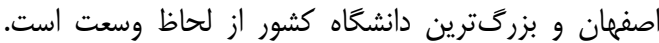

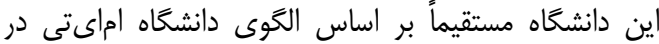

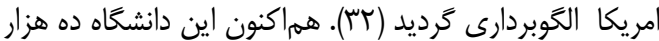

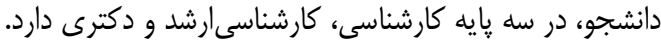

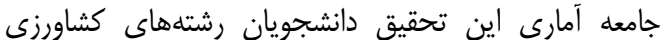

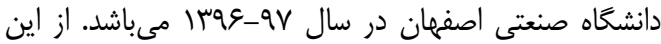

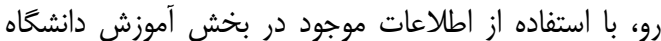

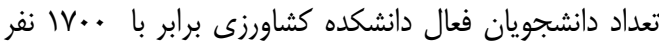

\section{تعداد}

جدول 1- سؤالات در يرسشنامه

\begin{tabular}{|c|c|}
\hline تعداد گويه & سؤالات \\
\hline$\wedge$ & ميزان أَكَاهى كارأفرينانه از طريق كانال ارتباطى \\
\hline$\Delta$ & مفهوم كار آفرينى از ديد دانشجويان \\
\hline 1 . & مفهوم آكاهى از فعاليتهاى دانشكدهها \\
\hline r & ويزگى هاى روانشناختى افراد \\
\hline rq & ويزگى هاى دانشكاه كار آفرين \\
\hline
\end{tabular}

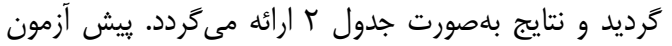

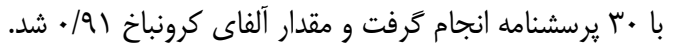

بلهنظور سنجش اعتبار و اعتماد ابزار تحقيق از روش أرئ

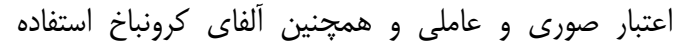

Table 2. Reliability of the research tool using Cronbach's alpha coefficient

جدول r- يايايى ابزار يزوهش با استفاده از ضريب آلفاى كرونباخ

\begin{tabular}{|c|c|}
\hline ألفاى كرونباخ & متغير \\
\hline.$/ 99$ & مفهوم كارأفرينى \\
\hline ./VD & كانال هاى اطلاعاتى \\
\hline.$/ v q$ & آكاهى از فعاليتهاى دانشكدهها \\
\hline . / T & \\
\hline$\cdot / \mathrm{VV}$ & ويزگ گهاى دانشخاه كارآفرين \\
\hline
\end{tabular}

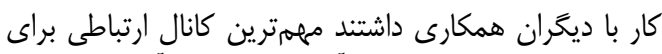

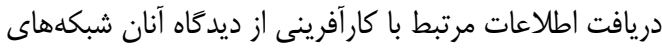

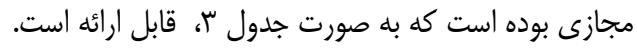

نتايج و بحث

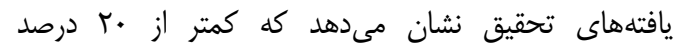

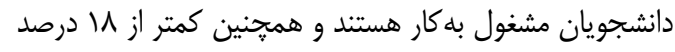

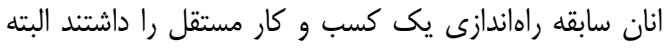

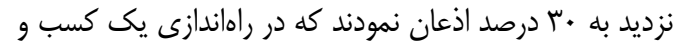

جدول ץ- گويههاى مورد بررسى در شاخص كانالهاى ارتباطى

Table 3. The survey items for communication channel index

\begin{tabular}{|c|c|c|c|c|}
\hline رتبه & $\mathrm{Cv}$ & انحراف معيار & ميانكين & كانالها \\
\hline$\Delta$ & \multirow{8}{*}{$\begin{array}{l}0 / 457 \\
0 / 482 \\
0 / 488 \\
0 / 536 \\
0 / 258 \\
0 / 276 \\
0 / 407 \\
0 / 366\end{array}$} & $1 / 1 \% q$ & $r / \notin q$ & تلويزيون \\
\hline 9 & &.$/ N F V$ & $1 / \Delta \Delta$ & راديو \\
\hline v & & $1 / \cdot v q$ & $r / r)$ & مجلهها و نشريهها \\
\hline$\wedge$ & & גז// & $r / T$ & روزنامه \\
\hline 1 & & .1998 & $r / v r$ & شبكههاى مجازى \\
\hline$r$ & & $1 / \cdots 1$ & $r / 9 \Delta$ & دوستان و آشنايان \\
\hline c & & $|/ r|$. & $r / a V$ & كتاب \\
\hline$r$ & & 1/NA & r r/r & آموزشهاى رسمى \\
\hline
\end{tabular}

و و نياز به موفقيت V VV درصد برآورد شده است. همجنين،

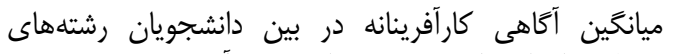

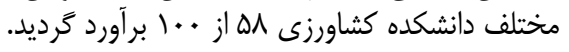

بلهاظ ويزگى هاى روانشناختى نيز مىتوان بيان نمود كه

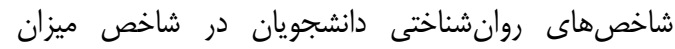

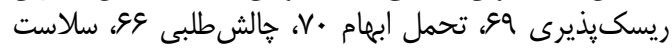

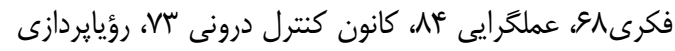


Table 4. Average rankings of students' awernance

جدول f- ميانكين رتبهايى ميزآن آكاهى دانشجويان

\begin{tabular}{|c|c|c|}
\hline ميانكين رتبهايى از .. ب واحد & تعداد افراد & دانشكدها \\
\hline $11 \mathrm{~V} / \mathrm{WV}$ & १1 & آكاهى كارآفرينانه دانشجويان \\
\hline 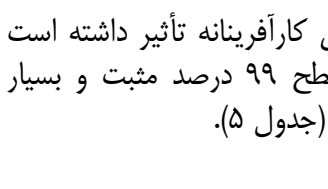 & 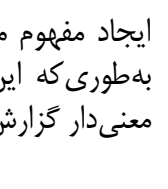 & 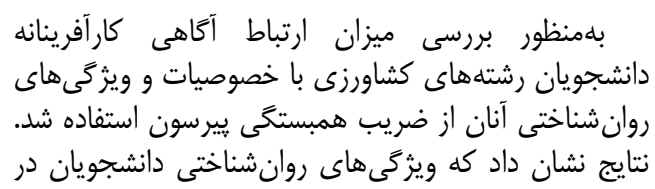 \\
\hline
\end{tabular}

جدول ه- آزمون همبستخى ييرسون بين آَاهى كارآفرينانه دانشجويان با ويثخى هاى روانشناختى Table 5. Pearson Correlation Test between Students' Entrepreneurial awernance and Psychological Characteristics

H. فرضيه

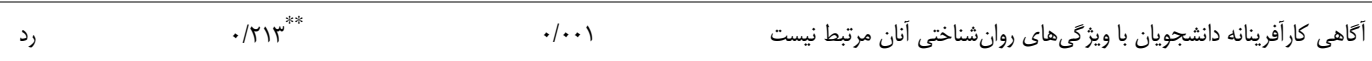

علامت (**) به اين معنى است كه رابطه بين دو متغير در سطح 9 درصد معنى دار مى باشد.

كارشناسى ارشد V/VA و دكترى D\&/F

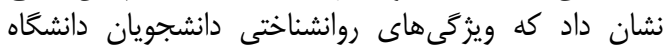

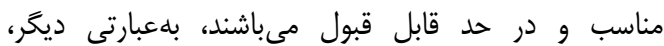

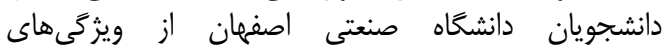

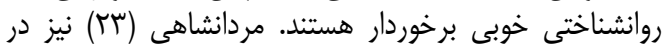

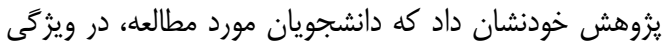

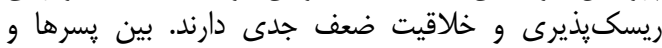

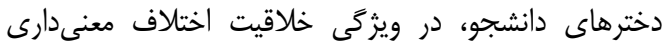

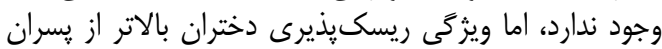

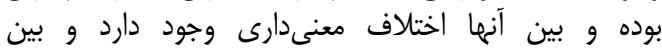

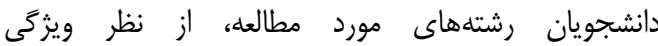

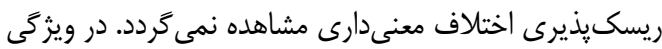

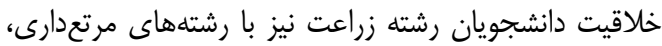

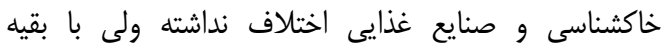
رشتها اختاسلاف دارند. از آنجايى كه نتايج تحقيق نشان دانداد داد كه ميزان آكاهى

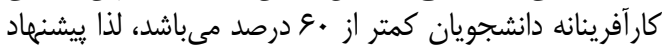

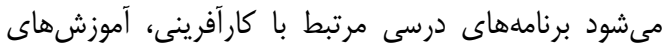

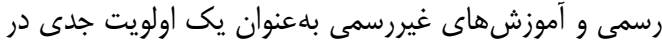

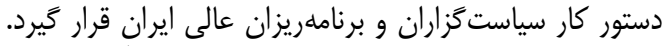

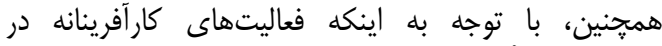

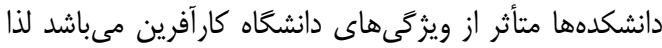

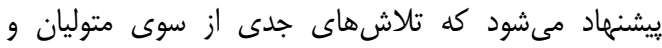

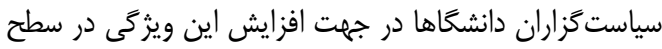

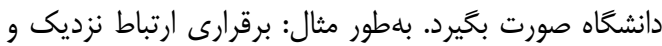

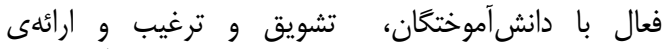

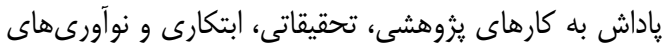

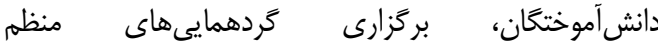

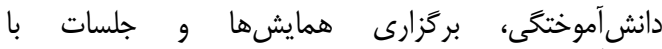

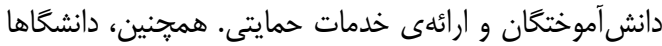

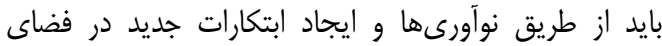

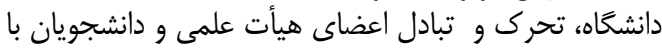

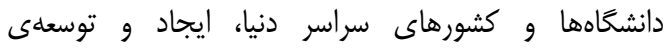

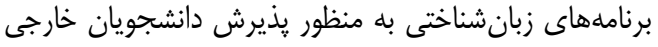
در بينالملىىسازى دانشخاه كوشش بنش كند.

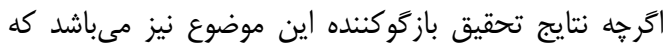

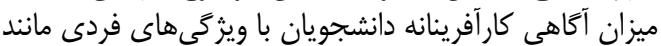

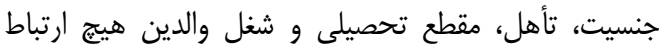

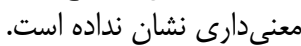

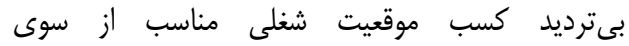

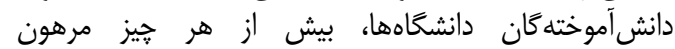

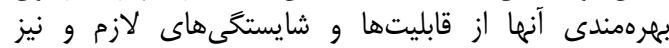

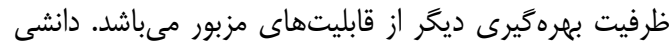

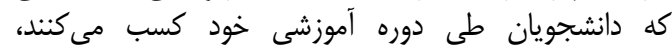

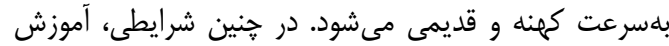

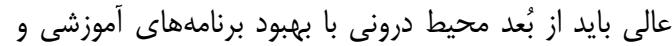

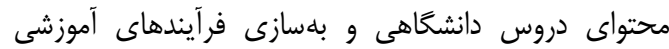

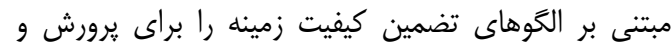

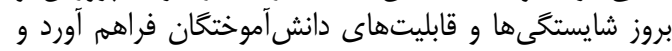

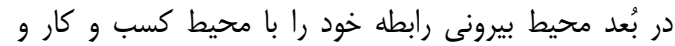

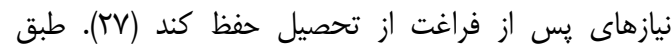
جارجوب نظرى تحقيق از بين كانالهاى ارئ ارتباطى (تلويزيون،

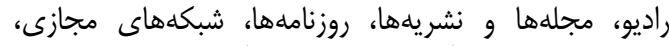

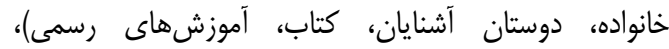

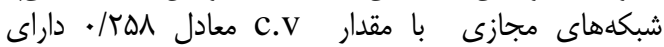

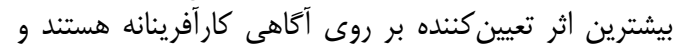

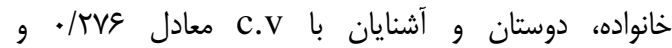

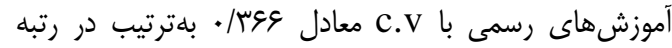
دوم و سوم قرار دارند.

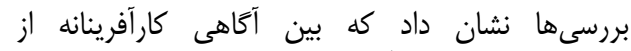

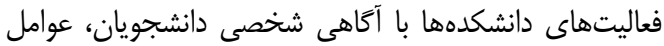

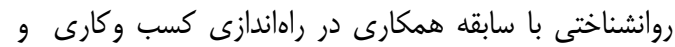

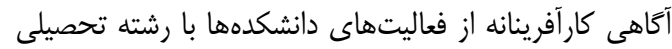

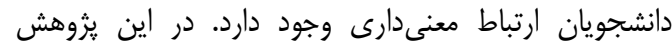

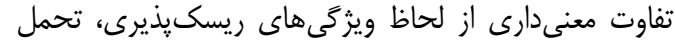

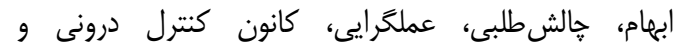

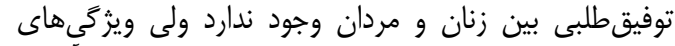

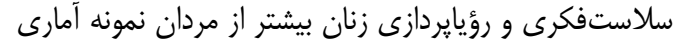

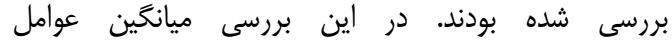

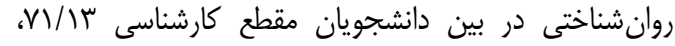


1. Abdollahi, H., J. Aghamohammadi, A.S. Abbaspour and A.H. Delaware. 2016. An Analysis of Personality Characteristics of Entrepreneurship among the Students in the First Level of Secondary Education in Kurdistan Province. Quarterly Journal of Invention and Creativity in the Humanities, 7: 70-49.

2. Ahmad Pourdariani, M. and M. Azizi. 2014. Entrepreneurship. Cultural and Publishing Institute of Mehrbar Pen, Tehran.

3. Allameh, S.M., M. Gharibpour and F. Amiri. 2013. Factors Affecting the Process of Production and Transfer of Knowledge in Small and Medium Business. Human Resource Management Research Institute of Imam Hossein University (AS), 5: 85-69.

4. Alwani, S.M., S.M. Moghimi, A.S. Azar and M.H. Rahmati. 2011. Policy in Entrepreneurship Education System in Iran. Work and Society Monthly Workbook, 140: 30-4.

5. Amiri Lorgani, M. 2016. Examination of Barriers to Academic Entrepreneurship at Gonbad University, Graduate Student in Entrepreneurship Management (Agribusiness Services). Faculty of Humanities Department of Economics. Gonbad Kavous University.

6. Arslan, C. Dilmac, B. and E. Hamarta. 2009. Coping with stress and trait anxiety in terms of locus of control: a study with Turkish university students. Social Behavior and Personality, 37: 791-800.

7. Clark, B.R. 1998. The entrepreneurial university: Demand and response. Tertiary. Education Management, 4: 5-16. doi/abs/10.1080/13583883.1998.9966941-

8. Collins, L., P.D. Hannon and A. Smith. 2004. Enacting entrepreneurial intent: the gaps between student needs and higher education capability. Education Train, 46: 454-463.

9. Cools, E. and H.W. Broeck. 2008. The hunt for the heffalump continues: can trait and cognitive characteristic predict entrepreneurial orientation? Journal of Small Business Management, 18: 23-41.

10. Cuervo, A., D. Ribeiro and S. Roig. 2007. Entrepreneurship: concepts, theory and perspective. Springer, Science Bus Media.

11. Etzkowitz, H. 2004. The evolution of the entrepreneurial university, International Journal technology Globalisation, 1: 64-77.

12. Gholam Rezaei, S., F. Sepahand, K. Naderi and N. Kakavand. 2017. Investigating the Role of the Agricultural Engineering and Natural Resources Organization in the Development of Entrepreneurship among Graduates. Quarterly Journal of Entrepreneurship Strategies in Agriculture, 4 (7): 56-48.

13. Gibb, A. 2002. In Pursuit of a New Enterprise and Entrepreneurship Paradigm for Learning: Creative Destruction, New Values, New Ways of Doing Things and New Combinations of Knowledge. Inte . Rnational Journal Management, 4: 233-269. doi.org/10.3402/aie.v3i0.17211

14. Gibb, A. 2002. Creating conducive environments for learning and entrepreneurship: living with, dealing with, creating and enjoying uncertainty and complexity. Ind. High. Educ, 16: 135-148.

15. Gibb, A. 2012. Exploring the synergistic potential in entrepreneurial university development: towards the building of a strategic framework. Annals of Innovation \& Entrepreneurship, 3: 1-21. doi/abs/10.3402/aie.v3i0.17211.

16. Golar, Z., M. Amiri and M. Moazami. 2017. Designing a Conceptual Framework for Stakeholder Engagement in Public Policy. Journal of Audit Knowledge, 17: 105-81.

17. Gurol, Y. and N. Atsan. 2006. Entrepreneurial characteristics amongst university students some insights for entrepreneurship education and training in Turkey. Education Train, 48: 25-38.

18. Hafezian, M. and M. Salehi. 2015. Identification of components in human resources management of university incubators and its role in creating productive companies of the university. Two-part research on human resource management at Imam Hossein University of Medical Sciences (AS), 4: 103-83.

19. Khosrowypour, B. and S.H. Kikhah. 2013. Entrepreneurship Education, an Approach to Agricultural Students' Employment. Monthly Social, Economic, Scientific and Cultural Work and Society, 163: 39-26.

20. Kianmehr, M. 2003. Considerations about the unemployment issue, with an emphasis on the issue of graduating unemployment in the country. Journal of Cooprative, 1: 18-13.

21. Kordinach, A., P. Ahmadi, Z. Ghorbani and N. Nikanlachi. 2012. Study of the characteristics of Entrepreneurial University at Tarbiat Modares University. Entrepreneurship Development 5: 64-47.

22. Mahmudnia, A., P. Najjarian, S. Zarghami and M. Yemeni. 2012. Edgar Moran's approach to philosophy and his philosophical foundations. Quarterly Journal of Interdisciplinary Studies in Humanities, 4: 86-65.

23. Mardanshahi, M. and M. Roshanfar. 2015. Formulation of Agricultural Entrepreneurship Development Strategies among Agricultural and Natural Resources Graduates. Strategies for entrepreneurship in agriculture, 2: 1-10.

24. Marlow, S. and M. McAdam. 2008. A preliminary investigation into networking activities within the university incubator. International journal entrepreneurship behavior research, 14: 219-241. 
25. Miraqa'i, A.S. and M. Mirzai. 2012. Investigating Personality Characteristics of Entrepreneurship among Technical and Engineering Students of Isfahan University. Iranian Engineering Education Quarterly, 14: 147-133.

26. Movahedi, R., H. Sa'adi, S. Akbari and M. Azizi. 2012. Pathology of Unemployed Agricultural Graduates: quantitative and qualitative analysis. Research on Agricultural Economics and Development, 4: 692-679.

27. Mradneshahi, M. and M. RoshanFar. 2015. Development of strategies for agricultural entrepreneurship development among agricultural and natural resource graduates. Journal of Entrepreneurship Strategies, 2(4): 10-1.

28. Rothaermel, F.T., S.D. Agung and L. Jiang. 2007. University entrepreneurship: Ataxonomy of the literature. Industrial and Corporate Change, 16: 691-791.

29. Safarzadeh, H., M. Ahmadi-Sharif and Gh. KargrainMarvesti. 2009 Factors Affecting the Establishment of Entrepreneurial Universities. Journal of Technology Education, 4: 151-137.

30. Samadimarkkala'i, H. 2015. Explaining the Status of Indicators of Entrepreneurial University in Higher Education with the Design of Empirical Research. Cultural Engineering, 10: 149-127.

31. Shariatzadeh, M., M. Chizari, A. Malek Mohammadi and A. Nowrooz. 2006. Opinions of Agricultural Education Experts on the Objectives, Plans and Process of Recruitment of Agricultural Agricultural Secondary School Students. Journal of Agricultural Extension and Training in Iran, 2: 14-1.

32. Strategic Plan of Isfahan University of Technology. Available on site: https://www.iut.ac.ir

33. Zali, M.R., M. Madhosh and A. Kordinach. 2007. Evaluation of entrepreneurship characteristics of students (Case study: Mazandaran University). Quarterly Journal of Humanities, 1: 81-113.

34. Zampetakis, L.A., K. Kafetsios, N. Bouranta, T. Dewett and V.S. Moustakis. 2009. on the relationship between emotional intelligence and entrepreneurial attitudes and intentions. International journal entrepreneurship behavior research, 15: 595-618. 


\title{
Studying the Entrepreneurial Characteristics of Agricultural Students (Case Study: Isfahn Uiversity of Technology)
}

\section{Mohammad Sadegh Ebrahimi ${ }^{1}$ and Ziba Bahrami ${ }^{2}$}

1- Assistant Professor of Isfahan University of Technology, Department of Rural Development, Faculty of Agriculture, Isfahan University of Technology (Corresponding author: ebrahimi_ms@cc.iut.ac.ir) 2- M.Sc. Isfahan University of Technology, Department of Rural Development, Faculty of Agriculture, Isfahan University of Technology

Received: May 4, 2019

Accepted: May 5, 2019

\begin{abstract}
Entrepreneurship is a source of flexibility, innovation, job creation for the economy, and an interesting opportunity for professional development. In this research, the role of the university in creating entrepreneurship awareness among the students of Isfahan University of Technology has been studied. The statistical population of this study is graduate, postgraduate, and undergraduate students who have completed at least two years of study. The research method was descriptive and analytic and a questionnaire was used. Content validity of the questionnaire was confirmed by using the Kmo coefficient and Bartlett's test and the reliability of the Cronbach's alpha coefficient was used, indicating that the instrument was stable at $91 \%$. Sample size was determined using Cochran formula and stratified sampling method with proportional assignment was used. As a sample, 98 students were selected in faculty of agricultural engineering. To analyze the data, descriptive and inferential statistics such as frequency, mean, Kruskal test, Mann-Whitney, Pearson correlation coefficient and regression were used. The results of the crolation analysis showed that thera are 99 percent significant relationship between the variables of the characteristics of the entrepreneurial university and the level of awareness of the entrepreneurial activities of the colleges.
\end{abstract}

Keywords: Educational System, Entrepreneurship, Innovation 